\title{
Knowledge, Attitudes and Practices of Bioethics among Doctors in a Tertiary Care Government Teaching Hospital in India
}

Misbahuddin Mohammad ${ }^{1 *}$, Farida Ahmad ${ }^{2}$, Syed Z Rahman ${ }^{3}$, Varun Gupta ${ }^{4}$ and Tariq Salman ${ }^{5}$

${ }^{1}$ King Abdulaziz University, Jeddah, Saudi arabia

${ }_{2}^{2}$ MBBS, MD, Aligarh Muslim University, India

${ }^{3}$ MBBS, MD, University of western sydney, Australia

${ }^{4} M B B S, M D$, Elsevier, India

${ }^{5} \mathrm{MBBS}, \mathrm{MD}$, Era Medical College, Uttarpradesh, India

\begin{abstract}
Human subjects' participation in medical research has often raised ethical concerns. After Nazi exploitation; various Guidelines \& Declarations were prepared, but still unethical behaviour of healthcare practitioners is being reported. After graduation and entering into practical field; sudden exposure to challenges makes it difficult to take decisions, which shows a lacuna in traditional medical training. There are debates about inclusion of practical ethics in medical curricula. Present study assesses the knowledge, attitude and practices of healthcare ethics among doctors in a government teaching hospital. A self-administered structured questionnaire was devised, tested and distributed $(\mathrm{n}=$ 172). Faculty and residents were compared using Chi square test and the residents' responses in different years of residency were compared using Chi square test followed by Kendall's tau-c test to find correlation. Faculty was more aware of the guidelines. About $77.8 \%$ faculty and $48.5 \%$ residents were aware of Institutional Ethical Committee (IEC), and about $37.5 \%$ from faculty and $23.5 \%$ from residents were satisfied with IEC. Faculty encountered ethical problems more often $(62.5 \%$ vs $45.5 \%)$ than residents. Source of knowledge of bioethics was multiple. Departmental lectures were not preferred mode of learning (8.8\%). Colleague was most preferred mode of consultation for any problem. Some residents faced ethical problem in publication. All faculty and $94.1 \%$ residents felt the need for further education on bioethics. There was negative correlation $(-0.3, p<0.001)$ between the frequency of ethical problems and residency years. There is an urgent need to include formal training of practical ethics and make departmental learning more interesting.
\end{abstract}

Keywords: Bioethics; Clinical research; Hippocratic Oath; KAP; Survey; Questionnaire

\section{Introduction}

The participation of human subjects in medical research has raised ethical concerns from time to time. After the gross exploitation of human subjects by the Nazi regime under the guise of medical research, the international community was bound to think in the direction of ethical regulations, so a number of Guidelines, Declarations, and Codes \& Reports were prepared [1-10]

However, in spite of all these guidelines, there are still a number of reported incidents of unethical behaviour of medical students and health practitioners with patients as well as colleagues [11-13]. This may be partly due to a lack of practical ethical guidance during the learning phase. Recently, In India, as the medical profession has been brought under "Consumer Protection Act" [14], there have been increasing complaints of poor ethical conduct against healthcare practitioners. This may be due to increased public awareness and inappropriate practices by the healthcare professionals.

After graduating the medical course and entering into practical field, the sudden exposure to various challenges makes it very difficult to take decisions encompassing the broader aspect of both scientific knowledge and human values. Medicine is holistic in nature and patient-physician relationship is its backbone [15,16]. Clinical knowledge alone is not sufficient to solve medical problems. Patients are more inclined to consult those physicians who have expert clinical knowledge, well aware of patients' needs and values, able to effectively engage in dialogue, communicate clinical knowledge with empathy and understanding, and embrace their broader concerns.

With the information explosion and increasing public awareness, physicians must be competent and compassionate. Future doctors and medical students must be provided excellent scientific knowledge within the context of the moral basis of their relationship with the patients and they must understand how the human values are embedded in clinical decision making. Though the current curriculum includes the topics related to ethics and there are studies stressing the importance of incorporating ethical and legal issues into medical curricula [17-19], still the traditional medical training offers little help in resolving the practical ethical problems encountered by healthcare professionals. There are opinions and debate on the subject of inclusion of formal education of practical ethics in medical curricula [20] as it has been found that ethics teaching has a profound influence on medical professionals' attitudes and decision making [21,22]. Moreover, some institutions have developed guidelines for ethics in clinical teaching and surgical residency programmes [23-25]. But the initial step in this direction is to determine the prevailing knowledge and attitude of healthcare professionals in the concerned region. In this regard, some studies have been done in the past in different regions [26-28]. The present study has been done to assess the knowledge,

*Corresponding author: Misbahuddin Mohammad, MD, King Abdulaziz University, Jeddah, Saudi arabia, E-mail: drmisbah98@gmail.com

Received August 01, 2011; Accepted October 19, 2011; Published October 22, 2011

Citation: Mohammad M, Ahmad F, Rahman SZ, Gupta V, Salman T (2011) Knowledge, Attitudes and Practices of Bioethics among Doctors in a Tertiary Care Government Teaching Hospital in India. J Clinic Res Bioeth 2:118. doi:10.4172/2155-9627.1000118

Copyright: @ 2011 Mohammad M, et al. This is an open-access article distributed under the terms of the Creative Commons Attribution License, which permits unrestricted use, distribution, and reproduction in any medium, provided the original author and source are credited. 
attitude and practices of healthcare ethics among medical professional in a government teaching hospital in India.

\section{Methods, population and data analysis}

A twenty item self-administered structured and validated questionnaire about knowledge, beliefs and attitudes towards principles and practice of bioethics in clinical research, informed consent and role of an ethics committee in a tertiary care teaching hospital was developed de novo, tested and reviewed by the Institutional Ethics Committee. It was made available to all consultant physicians \& senior residents (faculty) and junior residents at Jawaharlal Nehru Medical College, Aligarh, India (a tertiary care government teaching hospital) during January - February 2011. Respondents were selected on the basis of convenience sampling, and approached by at least one of the authors in person. The questionnaires were completed by the respondents in private and handed back to investigators in sealed, unmarked envelopes. The questionnaire included a full range of response options.

Prior to distribution of the questionnaire a pilot study was done with a selected group of physicians who were asked to fill out the questionnaire and return with comments and criticism. The initial part of the questionnaire consist of a section on demographics such as designation, graduating institute, taking of Hippocratic Oath after graduation and their current status of involvement in clinical research. The second part of the questionnaire assessed the awareness of the respondents about the codes, regulations and guidelines like (Nuremberg code, the Helsinki declaration, CIOMS guidelines, revised guidelines of ICMR for biomedical research on human participants), and the recent example of an unethical medical research in India.

Further, questions were asked about the respondent's knowledge of the presence of an ethics committee (IEC) in the institution, its composition, role and finally their satisfaction about the role of the ethics committee. They were also inquired whether all studies involving human beings need to be reviewed by IEC and what type of studies to be exempted. The respondents were questioned about the Informed consent in their research, was in local language and whether they give a copy of it to the patient.

In the final part of the questionnaire, respondents were enquired about the frequency of ethical problems encountered in research and publication, the source of knowledge of bioethics and the preference for consultation regarding an ethical problem should it arise. Finally they were asked whether they feel the need of educational activities in the field of bioethics in their institution.

Out of the 200 distributed questionnaires, 183 were returned of which 11 were not filled properly and were not included for analysis. The present paper analyses and compares the responses of the faculty and residents $(\mathrm{n}=172)$ among the survey. Data were analyzed using SPSS version 16.0 software. Descriptive analyses were done for all the data. The knowledge, attitudes and practices towards bioethics were compared between faculty and graduate medical students using a Chi square test. Additionally, the responses of graduates in different years of residency were compared using Chi square test followed by Kendall's tau-c test to find correlation between residency experience and knowledge, attitudes and practices towards bioethics. A p value of $(<0.05)$ was considered statistically significant.

\section{Results and Discussion}

The findings of the present study clearly show the difference in the knowledge and attitudes between faculty and residents. Table 1 shows the basic demography of the respondents. All the faculty members and about $76.5 \%$ of the residents included in the study graduated from same college. Moreover, about $21 \%$ of the residents and $33 \%$ of the faculty have formally taken Hippocratic Oath. $71 \%$ of the residents and $89 \%$ of the faculty was actively involved in research. Table 2 shows the knowledge of different guidelines among residents and faculty. As expected, faculty was more aware of the guidelines than residents owing to their long involvement in research, but still the number is far from satisfaction. No significant difference was found between residents and faculty regarding the awareness of a recent unethical renal cell carcinoma drug trial.

Table 3 compares the knowledge, attitude \& practice of faculty with residents regarding Institutional Ethics Committee (IEC). The unawareness regarding the ethical committee in the present study is more than the previous studies [26,27]. There was a significant difference between faculty and residents about the awareness of institutional ethics committee, but not regarding its composition. Majority of the residents and faculty were of the opinion that dean is the chairman of IEC. As expected, significantly greater numbers of projects were submitted to the IEC by the faculty as compared to residents. About $37.5 \%$ of the faculty and $23.5 \%$ of the residents were satisfied with the functioning of the IEC. Majority of the faculty thought that all studies involving human beings should be reviewed by IEC, while some thought that retrospective studies should be exempted. In contrast, most residents

\begin{tabular}{|l|l|l|}
\hline CATEGORY & NUMBERS & PERCENTAGE \\
\hline Faculty & 36 & 20.9 \\
\hline Residents (Total) & 136 & 79.1 \\
\hline JR I & 28 & 16.2 \\
JR II & 32 & 18.6 \\
\hline JR III & 76 & 44.3 \\
\hline
\end{tabular}

Table 1: Basic demography.

\begin{tabular}{|l|l|l|}
\hline Guidelines & Residents (\%) & Faculty (\%) \\
\hline Nuremberg Code & 11.1 & 17.6 \\
\hline Helsinki Declaration* & 22.2 & 47.1 \\
\hline Revised ICMR guidelines & 22.2 & 21.2 \\
\hline CIOAMS Guidelines* & 2.7 & 9.6 \\
\hline
\end{tabular}

$\left({ }^{*}\right.$ indicates $\left.\mathrm{p}<0.05\right)$

Table 2: Awareness of different guidelines among faculty \& residents.

\begin{tabular}{|c|c|c|}
\hline Questions & Faculty $\%$ & Residents \% \\
\hline Awareness about the IEC in institute ${ }^{*}$ & 77.8 & 48.5 \\
\hline $\begin{array}{l}\text { Submission of application to IEC for review of research } \\
\text { work* }\end{array}$ & 62.5 & 32.4 \\
\hline $\begin{array}{l}\text { Pursuance of research work even after rejection of } \\
\text { application* }\end{array}$ & 0 & 21.1 \\
\hline Awareness regarding the composition of IEC & 44.4 & 29.4 \\
\hline $\begin{array}{l}\text { Who is the chairman of IEC* } \\
\text { Dean } \\
\text { Principal } \\
\text { CMS } \\
\text { Others } \\
\text { Don't know }\end{array}$ & $\begin{array}{l}50.0 \\
0 \\
0 \\
37.5 \\
12.5 \\
\end{array}$ & $\begin{array}{l}60.0 \\
3.3 \\
10.0 \\
0 \\
26.7\end{array}$ \\
\hline IEC of the institution is playing its role properly & 37.5 & 23.5 \\
\hline $\begin{array}{l}\text { Need of all studies involving human beings to be } \\
\text { reviewed by IEC* }\end{array}$ & 71.4 & 33.3 \\
\hline $\begin{array}{l}\text { If no, then what types of studies are exempted* } \\
\text { Retrospective } \\
\text { Survey } \\
\text { Don't know }\end{array}$ & $\begin{array}{l}66.7 \\
0 \\
33.3\end{array}$ & $\begin{array}{l}23.8 \\
61.9 \\
14.3\end{array}$ \\
\hline
\end{tabular}

Table 3: Knowledge, attitude \& practice of faculty and residents regarding IEC. 


\begin{tabular}{|l|l|l|}
\hline Questions & Faculty \% & Resident \% \\
\hline Taking of written informed consent* & 100.0 & 64.5 \\
\hline In local language & 50.0 & 39.3 \\
\hline According to the format of ICMR & 37.5 & 29.6 \\
\hline $\begin{array}{l}\text { Provide a copy of written informed consent to the } \\
\text { patients }\end{array}$ & 10.0 & 15.2 \\
\hline
\end{tabular}

Table 4: Showing the responses to questions on informed consent.

said that there is no need of IEC review for survey and retrospective studies. No faculty member was willing to pursue research proposal after rejection by IEC, while $21.1 \%$ of the residents would prefer to continue even after rejection by IEC. This may be due to the fact, that at early career stage, they do not give much consideration to the ethical aspects.

Table 4 shows that all the faculty members take written informed consent. Moreover, they are more adhered to standard format as evident by the responses. Overall, attitude to provide a copy to the patient is more in residents; they probably consist of those residents associated with particular faculty members who also provide a copy to patients. Half of the faculty and $68.8 \%$ of the residents said that there is involvement of bioethics while publication in peer-reviewed journals. Some of the residents faced ethical problem while publishing their studies. Faculty responded that they encountered ethical problems in clinical practice \& research more often $(62.5 \%$ vs $45.5 \%)$ than the residents; this may be due to referral of such cases by the residents to the faculty, which adds to their own cases. It implies that both the junior and senior staff needs to be included while offering training.

Figure 1 depicts the source of knowledge of bioethics among faculty and residents. Very few respondents had obtained their knowledge of ethics from a single source. Media is the most common source for the faculty while books \& journals are the preferred mode for residents. An important finding is that $22 \%$ of the residents do not find any reliable source for consultation. Another concern is that, departmental lectures are not playing an important role and they are not a much preferred mode of learning for residents as well as faculty (8.8\%). This shows that the curricular training regarding bioethics is either inadequate or ineffective. Healthcare personnel receive limited formal training in ethics even though their daily work involves direct and often crucial intervention in others' lives [26]. There is a need to revitalize this aspect; as for their entire training period, the residents remain attached to the department and for most of the career, the faculty remains attached. Departmental lectures can play a significant role in upgrading the knowledge and modifying the attitude \& practices of faculty and residents.

Figure 2 shows the preference of consultation of residents and faculty in case of an ethical problem. It is interesting to note that colleague was the most preferred mode of consultation in case of an ethical problem by faculty as well as residents; so a sound knowledge of bioethics becomes very imperative in this scenario to avoid misguidance of the peers. Moreover, the second most preferred mode for the residents was guide / HOD which is from faculty; and the faculty is mainly depending on colleague and miscellaneous sources, so ultimately good training for the faculty is more important than residents. All the faculty members and approximately $94.1 \%$ of the residents felt the need for lectures / conferences / symposia / CME / workshop etc on bioethics in the institution.

There was a weak correlation $(r=0.2, p<0.05)$ between the knowledge of ethical guidelines and residency year but no significant difference was found between the residency year and the recent awareness about an unethical carcinoma trial. As expected, approximately 14.3\%, 75\% and $89.5 \%$ of JR I, JR II and JR III respectively were actively engaged in research. All the residents in $1^{\text {st }}$ and $2^{\text {nd }}$ year and about $90 \%$ in final year felt the need for lectures / conferences / symposia / workshop / CMEs etc on bioethics in the institution.

Table 5 shows the correlation between residency years and knowledge, attitude \& practice regarding Institutional Ethical Committee ( ${ }^{*}$ denotes $\left.\mathrm{p}<0.05\right)$. There is a weak but significant correlation in two questions; more number of $2^{\text {nd }}$ year residents submit application to IEC owing to the allotment of thesis topic in JR II.

Source of knowledge of bioethics

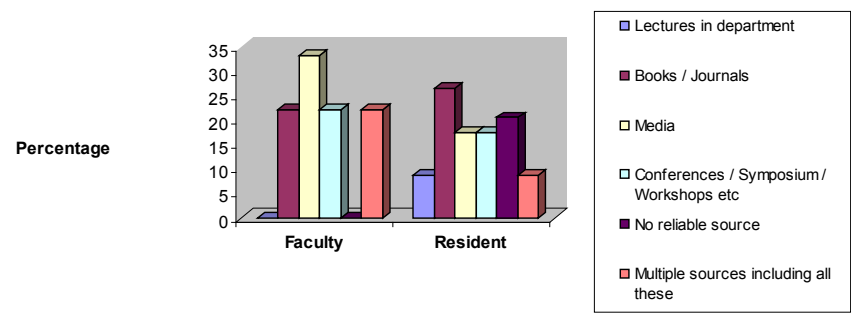

Figure 1: Source of knowledge of bioethics among faculty \& residents*.

Preference of consultation in case of an ethical problem

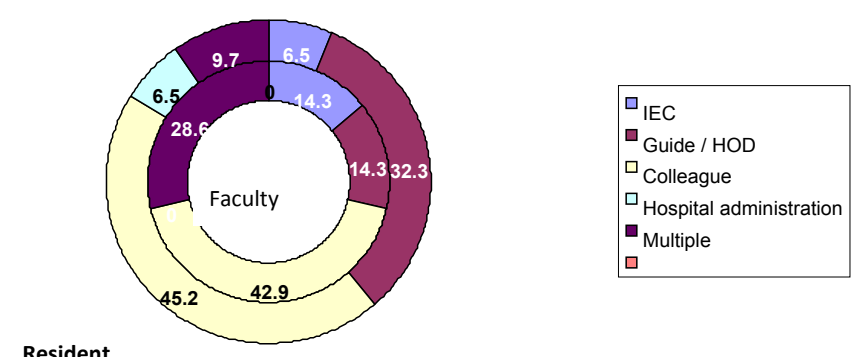

Figure 2: Preference of consultation in case of an ethical problem*.

\begin{tabular}{|c|c|c|c|c|}
\hline Questions & JR I & JR II & JR III & $R$ value \\
\hline Awareness about the IEC in institute & 33.3 & 50.0 & 52.6 & 0.11 \\
\hline $\begin{array}{l}\text { Submission of application to IEC for review of } \\
\text { research work }{ }^{*}\end{array}$ & 28.6 & 37.5 & 31.6 & 0.18 \\
\hline $\begin{array}{l}\text { Pursuance of research work even after rejection } \\
\text { of application }\end{array}$ & 0.0 & 12.5 & 16.7 & 0.32 \\
\hline Awareness regarding the composition of IEC & 14.3 & 37.5 & 32.6 & 0.09 \\
\hline Could a non-medic be member of IEC & 28.6 & 75.0 & 38.9 & 0.17 \\
\hline $\begin{array}{l}\text { Who is the chairman of IEC } \\
\text { Dean } \\
\text { Principal } \\
\text { CMS } \\
\text { Others } \\
\text { Don't know }\end{array}$ & $\begin{array}{l}50.0 \\
0.0 \\
0.0 \\
0.0 \\
50.0\end{array}$ & $\begin{array}{l}66.7 \\
0.0 \\
0.0 \\
0.0 \\
33.3\end{array}$ & $\begin{array}{l}61.1 \\
5.6 \\
16.7 \\
16.7 \\
0.0\end{array}$ & -0.12 \\
\hline IEC of the institution is playing its role properly & 28.6 & 25.0 & 21.1 & 0.07 \\
\hline $\begin{array}{l}\text { Need of all studies involving human beings to } \\
\text { be reviewed by IEC* }\end{array}$ & 16.7 & 25.0 & 42.1 & 0.23 \\
\hline $\begin{array}{r}\text { If no, then what types of studies are exempted } \\
\text { Retrospective } \\
\text { Survey } \\
\text { Don't know }\end{array}$ & $\begin{array}{l}33.3 \\
66.7 \\
0.0\end{array}$ & $\begin{array}{l}40.0 \\
60.0 \\
0.0\end{array}$ & $\begin{array}{l}15.4 \\
61.5 \\
23.1\end{array}$ & 0.31 \\
\hline
\end{tabular}

Table 5: Showing the correlation between residency years and knowledge, attitude \& practice regarding IEC ( ${ }^{*}$ denotes $p<0.05$ ). 
Citation: Mohammad M, Ahmad F, Rahman SZ, Gupta V, Salman T (2011) Knowledge, Attitudes and Practices of Bioethics among Doctors in a Tertiary Care Government Teaching Hospital in India. J Clinic Res Bioeth 2:118. doi:10.4172/2155-9627.1000118

Moreover; as the residency year increases, residents feel that all studies involving human beings should be reviewed by IEC.

As depicted in Figure 3, there is highly significant negative correlation $(-0.3, \mathrm{p}<0.001)$ between the frequency of ethical problems encountered and residency years. Frequency of ethical problems is increasing with the residency period; this is very much expected as final year residents are more involved in research and they might be

\section{Year of residency and Frequency of ethical problems}

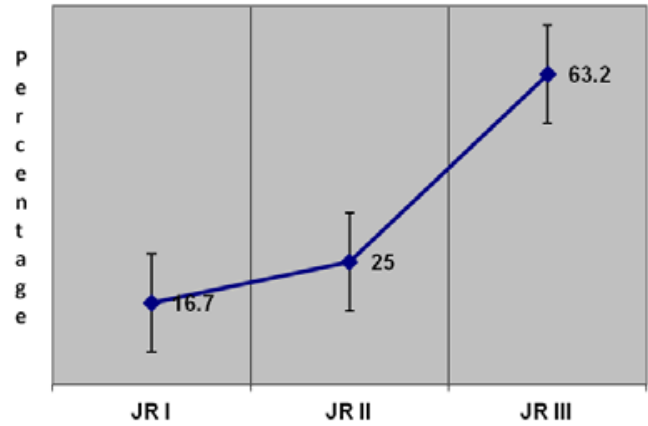

$(R=-0.3, p<0.001$

Figure 3: Relation between the residency year \& frequency of ethical problems

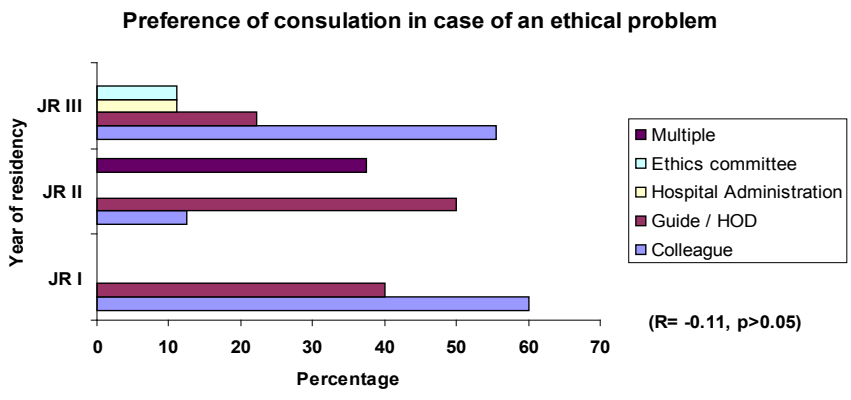

Figure 4: Preference of consultation in case of an ethical problem.

Residency years and knowledge, attitude \& practice regarding informed consent

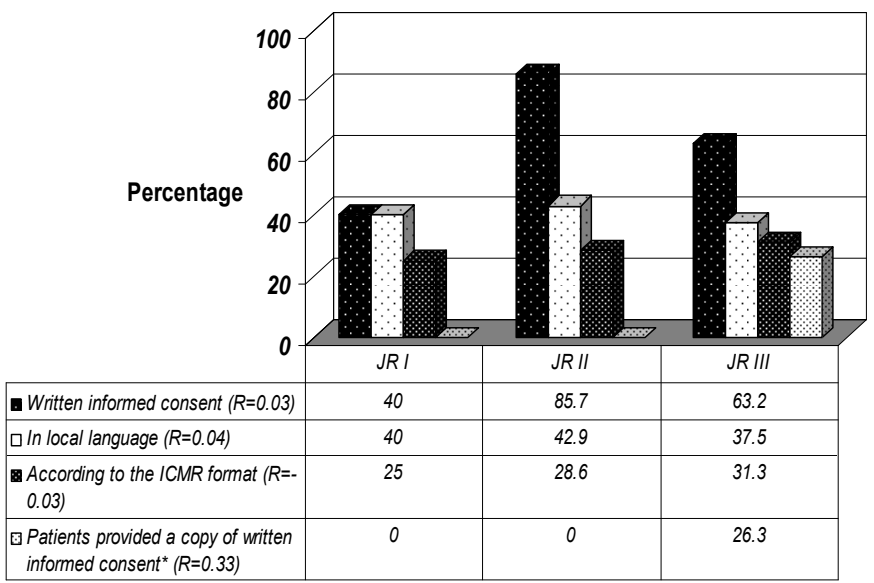

Figure 5: Correlation between residency years and knowledge, attitude \& practice regarding informed consent. overemphasizing trivial issues. The source of knowledge of bioethics among residents was multiple for example departmental lectures, books, journal, media, conferences, workshops and other sources, and no significant correlation was found between residency years and source of knowledge of bioethics. No significant correlation was found between the residency years and preference of consultation for an ethical problem. Multiple modes of consultation, like ethical committee, hospital administration, guide/HOD etc were there in case of an ethical problem, but most residents preferred to first consult their colleagues as they are most easily approachable and understandable. There was no significant correlation between residency years and knowledge, attitude \& practice regarding informed consent except that more number of final year residents provide a copy of informed consent to patient. This may be explained by the fact that final year residents are more knowledgeable than their juniors.

\section{Conclusion}

Physicians very frequently come across ethical dilemmas in their day to day practice. They are not provided formal training in practical aspects of ethics in their medical curricula. In addition to this; as the findings of the study identify that departmental lectures/teaching is also not very favorable among them, so there is an urgent need to include practical education of ethics, that too in an interesting manner, particularly in a multidisciplinary setting, to bridge the gap in the knowledge, attitude and practices regarding ethics in clinical practice $\&$ research. The state of medical education in India presents a scenario marked by rhetoric and wishful thinking rather than concrete steps in right direction.

\section{References}

1. The Nuremberg Code (1949) Trials of War Criminals before the Nuremberg Military Tribunals under Control Council Law No. 10, Washington DC: US Government Printing Office 2: 181-182.

2. National Commission for the Protection of Human Participants. Belmont Report (1978) Ethical and Guidelines for the Protection of Human participants of Research. Washington DC: US Government Printing Office.

3. Council for International Organizations of Medical Sciences (CIOMS) (1993) International Ethical Guidelines for Biomedical Research Involving Human Subjects. Geneva: Council for International Organizations of Medical Sciences.

4. Medical Research Council of Canada (1987) Guidelines on Research Involving Human Subjects. Ottawa: Medical Research Council.

5. World Health Organization and the Council for International Organizations of Medical Sciences (1982) Proposed International Guidelines for Biomedical Research Involving Human Subjects: A Joint Project of the World Health Organization and the Council for International Organizations of Medica Sciences. Geneva: Council for International Organizations of Medical Sciences.

6. Indian Council of Medical Research (2000) Ethical Guidelines for Biomedical Research on Human Subjects. New Delhi.

7. United Nations Educational, Scientific and Cultural Organisation (UNESCO) Universal Declaration on Bioethics and Human Rights (2005) Paris.

8. World Medical Organization (1996) Declaration of Helsinki. British Medica Journal (7 December) 313: 1448-1449.

9. World Medical Association (1949) International code of medical ethics. World Medical Association Bulletin 1: 109-111.

10. Declaration of Geneva (1948). Adopted by the General Assembly of World Medical Association at Geneva Switzerland.

11. Green MJ, Farber NJ, Ubel PA, Mauger DT, Aboff BM, et al. (2000) Lying to each other: when internal medicine residents use deception with their colleagues. Arch Intern Med 160: 2317-2323.

12. Baldwin DC Jr, Daugherty SR, Rowley BD, Schwarz MD (1996) Cheating in medical school: a survey of second year students at 31 schools. Acad Med 71: 267-273. 
Citation: Mohammad M, Ahmad F, Rahman SZ, Gupta V, Salman T (2011) Knowledge, Attitudes and Practices of Bioethics among Doctors in a Tertiary Care Government Teaching Hospital in India. J Clinic Res Bioeth 2:118. doi:10.4172/2155-9627.1000118

13. Baldwin DC Jr, Daugherty SR, Rowley BD (1998) Unethical and unprofessional conduct observed by residents during their first year of training. Acad Med 73: 1195-1200.

14. The consumer Protection Act (1986).

15. Tauber Al (1999) Confessions of a Medicine Man. An Essay in Popular Philosophy. Cambridge MA: MIT Press.

16. Tauber Al (2002) The ethical imperative of holism in medicine. In: Promises and Limits of Reductionism in the Biomedical Sciences. West Sussex: John Wiley \& Sons.

17. Mattick K, Bligh J (2006) Teaching and assessing medical ethics: where are we now? J Med Ethics 32: 181-185.

18. Eckles RE, Meslin EM, Gaffney M, Helft PR (2005) Medical ethics education: where are we? Where should we be going? A review. Acad Med 80: 11431152.

19. Roff S, Preece P (2004) Helping medical students to find their moral compasses: ethics teaching for second and third year undergraduates. J Med Ethics 30: 487-489.

20. McKneally MF, Singer PA (2001) Bioethics for clinicians: Teaching bioethics in the clinical setting. CMAJ 164: 1163-1167.
21. Sulmasy DP, Geller G, Levine DM, Faden RR (1993) A randomized trial of ethics education for medical house officers. J Med Ethics 19: 157-163.

22. Elger BS, Harding TW (2002) Terminally ill patients and Jehovah's witnesses: teaching acceptance of patients' refusals to vital treatments. Med Educ 36: 479-488.

23. Angelos $P$, Lafreniere R, Murphy TF, Rosen W (2003) Ethical issues in surgica treatment and research. Curr Probl Surg 40: 353-448.

24. Guidelines for ethics in clinical teaching (2002) Toronto: University of Toronto Faculty of Medicine.

25. Singer PA (2003) Intimate examinations and other ethical challenges in medica education. BMJ 326: 62-63.

26. Seetharaman H, Ramesh J, Errol W, Harley M (2006) Knowledge, attitudes and practice of healthcare ethics and law among doctors and nurses in Barbados. BMC Medical Ethics 7: 7

27. Hern GH Jr (1990) Ethics and human values committee survey: (AMI Denve Hospitals: Saint Luke's, Presbyterian Denver, Presbyterian Aurora: Summe 1989) A study of physician attitudes and perceptions of a hospital ethics committee. HEC Forum 2: 105-125.

28. Shirazi B, Shamim MS, Ahmed A (2005) Medical ethics in surgical wards: knowledge, attitude and practice of surgical team members in Karachi. Indian J Med Ethics 2: 94-96. 